\title{
IN DEFENSE OF CONTENT-INDEPENDENCE
}

\author{
N. P. Adams
}

In this paper I articulate and defend an improved understanding of contentindependent reasons. Content-independent reasons are a topic of particular interest in political philosophy and philosophy of law because of their connection to political obligation and political authority. ${ }^{1}$ In its classic form the question of political obligation is whether citizens have a moral obligation to obey every law because of its status as law, regardless of the particular content of the law. The question of political obligation comes down to whether there is a general contentindependent obligation to obey the law.

Recent discussions have been quite skeptical of whether citizens have a

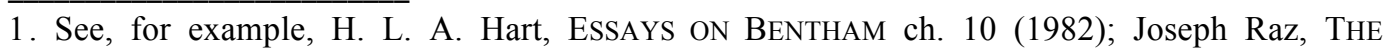
Morality of Freedom 35-37 (1986); Leslie Green, The Authority of the State 36-48 (1988); Andrei Marmor, Authorities and Persons, 1 Legal Theory 337 (1995); Thomas May, On Raz and the Obligation to Obey the Law, 16 LAW AND PHILOSOPHY 19 (1997); Christopher W. Morris, An Essay on the Modern State 207 (1998); Scott Shapiro, On Hart's Way Out, 4 Legal Theory 469 (1998); Kenneth Einar Himma, H. L. A. Hart and the Practical Different Thesis, 6 Legal Theory 1 (2000); John Gardner, Legal Positivism: 5 1/2 Myths, 46 AM. J. JuRIS. 199 (2001); Stephen Perry, Law and Obligation, 50 AM. J. JuRIS. 263 (2005); George Klosko, Are Political Obligations Content Independent?, 39 Political Theory 498 (2011); Noam Gur, Are Legal Rules Content-Independent Reasons?, 5 ProblemA 175 (2011); Daniel Viehoff, Democratic Equality and Political Authority, 42 PHIL. \& PUB. AfF. 337 (2014). As this list shows, issues surrounding content-independence are also important in a wide variety of debates beyond political obligation, especially in philosophy of law. 
general content-independent obligation to obey the law. This skepticism has led some, most prominently A. John Simmons, to embrace philosophical anarchism. ${ }^{2}$ In order to avoid this anarchism, others have instead rejected contentindependence as a condition on genuine political obligation. ${ }^{3}$ One of the main benefits of getting clear on the notion of content-independence is the clarity it brings to this debate and many related to it. ${ }^{4}$

I proceed in four sections. I first articulate and defend my understanding of content-independent reasons. In the second section I explain how my understanding of content-independence answers one of its most pervasive puzzles: how content-independence can be consistent with the fact that egregiously unjust laws cannot morally obligate citizens. Third, I show how my understanding of content-independence grounds replies to two conceptual challenges. ${ }^{5}$ In the fourth section I turn to the political realm and show why the notion of content-independence remains central to issues of political obligation and authority.

2. A. John Simmons, Moral Principles AND Political Obligations (1979).

3. See Klosko, supra note 1, at 516.

4. Green, supra note 1 , at 226 claims content-independence is necessary "in any argument purporting to establish the existence of a political obligation"; Hart, supra note 1, at 268 notes that it is one of the "elements which are crucial to the understanding of law."

5. P. Markwick, Law and Content-Independent Reasons, 20 OXFORD J. LEGAL STUD. 579 (2000) and Independent of Content, 9 Legal THEORY 43 (2003); Stefan Sciaraffa, On ContentIndependent Reasons: It's Not in the Name, 28 LAW AND PHILOSOPHY 233 (2009). 


\section{CONTENT-INDEPENDENCE}

A (practical) reason is a fact that counts in favor of an agent acting in some way. ${ }^{6}$ So, for example, the fact that exercising makes me healthier counts in favor of me exercising, so that fact is a reason for me to exercise. ${ }^{7}$ This example demonstrates the way reasons normally work. When considering some act, like exercising, I examine the merits of exercising, like the fact that it will make me healthier, as well as the demerits of exercising, like the fact that it will be time-consuming. These features of exercising are reasons for me to exercise or to refrain from exercising. I then balance my various reasons to determine whether, all things considered, I should exercise.

Content-independent reasons work differently. The most discussed

6. In contrast to practical reasons, theoretical reasons count in favor of believing rather than acting. I will only be concerned with practical reasons in this paper and should be understood to be referring to practical reasons when I use 'reason' in this paper. That said, theoretical reasons can also be content-independent, which is important for characterizing some phenomena such as expertise and testimony (compare Hart, supra note 1, at 261, although Marmor disagrees). I think the account of content-independence presented here can be applied equally well to theoretical reasons but that goes beyond the scope of this paper.

7. On reasons as facts, see Joseph Raz, PRACTICAl Reasons AND Norms 17-19 (2nd ed., 1999). My view that reasons are facts makes a significant difference to my arguments below. If reasons are propositions or mental states as some claim, then it is not clear whether I have a case against Markwick in section three, for example. I think the best view of reasons is that they are facts but clearly I cannot engage that debate here. 
example of a content-independent reason is a command issued by an authority. Imagine a parent exercising parental authority over her child and commanding the child to go to bed. If the child asks why she should go to bed, i.e. if the child asks for reasons, a paradigmatic parental response is "Because I told you to." With this response the parent does not appeal to the merits of going to bed, like the benefits of a good night's sleep, or the demerits of not going to bed, like being tired in the morning. Instead, the parent appeals to something that has nothing to do with the merits or demerits of going to bed at all: the fact that the parent commanded the child. The fact of the command is a reason for the child to act, but it is not one of the merits or demerits of what was commanded.

The most distinctive and important characteristic of content-independent reasons is the way they sever the normal connection between the merits and demerits of acting in some way and whether one has a reason to act in that way. ${ }^{8}$ If I am commanded to exercise, I now have a reason to exercise that is not one of those valuable features of exercise that I normally consider. While we understand why the health benefits of exercise counts in favor of exercising, it is unclear under why the "extraneous" fact of the command should count in favor in the same way. ${ }^{9}$ Indeed, this is one reason why theorists have embraced philosophical anarchism, for they do not see how an autonomous moral agent could be justified in ignoring the character of the action she was taking and relying on extraneous

8. Compare Hart, supra note 1, at 254-255.

9. Raz, supra note 1 , at 35 . 
facts, especially extraneous facts regarding the fallible will of others. ${ }^{10}$

For all its oddness, content-independence appears to be a theoretically useful concept. Most influentially, H. L. A. Hart used content-independent reasons to analyze the commands of an authority, following insights from Hobbes and Bentham and followed by many others. ${ }^{11}$ It is also used more widely, for example to analyze promises, ${ }^{12}$ decisions, ${ }^{13}$ and requests. ${ }^{14}$ Furthermore, the contrasting notion of content-dependence has been used to fruitfully analyze advice. $^{15}$

Unfortunately this useful notion is unclear and has often been characterized in a quite hasty and imprecise manner. Here is Joseph Raz's characterization of content-independent reasons: "A reason is contentindependent if there is no direct connection between the reason and the action for which it is a reason." ${ }^{16}$ Hart says a command "is intended to function as a reason independently of the nature or character of the actions to be done." 17 This is

10. R. P. Wolff, IN DEFENSE OF ANARCHISM (1970).

11. Hart, supra note 1.

12. Hart, supra note 1, at 255; Raz, supra note 1 , at 35.

13. Raz, supra note 7 , at 70 .

14. Raz, supra note 1, at 36; Shapiro, supra note 1, at 493; Marmor, supra note 1, at 355.

15. Raz, supra note 1 , at 54.

16. Raz, supra note 1, at 35; compare Marmor, supra note 1, at 345 and Joseph Raz, THE AUTHORITY OF LAW 234 (2nd ed., 2009).

17. Hart, supra note 1, at 254-255 and Legal and Moral Obligation, in ESSAYS IN MORAL Philosophy (A. I. Melden ed., 1958). Among others, Shapiro and Green similarly focus on the 
essentially the extent of their discussions of the meaning of the term; early on, Hart expresses his hope that the idea will be "self-explanatory." ${ }^{18}$ Yet these characterizations raise more questions than they answer. What is the nature of this "direct connection?"19 In what sense does the reason function "independently?" As noted by Andrei Marmor, far from being self-explanatory, "the notion of content-independence is notoriously difficult to define." ${ }^{20}$ Thus, despite the evident usefulness of the ideas of content-independence and content-dependence, they have led to considerable confusion, as we will see in more detail below.

In order to understand content-independence, we need to get clear on three issues: 1) what the relevant content is, 2) in what sense the reason is independent of said content, and 3) what the reason is dependent on, given that it is not dependent on content.

I begin with the third issue, which will shed light on the first two. The parental example is instructive. When saying that the reason for the child to go to bed was "Because $I$ told you to," the parent is highlighting a feature of the command that is not about the content of the command. In this case it is about who issued the command, or what I will call the command's source. ${ }^{21}$ This

nature of the act.

18. Hart, supra note 17 , at 100.

19. See Sciaraffa, supra note 5, at 242-243 for some worries about this notion of a direct connection.

20. Marmor, supra note 1 , at 345.

21. In his notebooks, Hart called the insight that rules could bind in virtue of their "source" rather than their content "revelatory." Nicola Lacey, A LifE OF H. L. A. HART: THE Nightmare AND THE 
hearkens back to Hobbes, who wrote that "Command is where a man saith, 'Doe this,' or 'Doe not this,' without expecting other reason than the will of him that says it." ${ }^{, 2}$ According to Hobbes, the reason to do as commanded depends on a feature of the source of the command ("him that says it"), not a feature of what was commanded.

To see this more clearly, consider two variations on the parent case. In the first variation, the parent says, "Eat your peas" instead of "Go to bed." This changes the content of the command but keeps the source constant. In the second variation on the original case, a stranger commands the child to go to bed, changing the source but keeping the content constant. The question is whether the child has an obligation to obey in the variations. The answer is obviously that the child has an obligation in the first variation but not in the second variation. The stranger lacks the parent's standing so cannot issue commands to bind the child; the child does not have an obligation to go to bed just because a stranger told her to. But the child does have an obligation to eat her peas just because her parent told her to, just as she has an obligation to go to bed if her parent says to. Changing the content of the command does not change whether the child is obligated, but changing the source does. That is, whether the command is a reason for the child to obey depends on features of the command's source, not on features of the command's content. It is therefore natural to say that a command is a content-independent but source-dependent reason (or what one might call an

NOBLE DREAM 227 (2006).

22. Thomas Hobbes, LeVIATHAN 176 (Richard Tuck ed., 1991). 
exclusively source-dependent reason).

The lesson of this example is that content-independence necessarily calls attention to the fact that the reason depends on something other than the content. The fact that you were commanded to act can be a content-independent reason because there is something other than features of the command's content that the reason can depend on, namely features of the command's source. In order to make sense of content-independence, we need this contrast with content. In more general terms, a command can be a content-independent reason only because the command itself is a container. A command is a speech act that has referential content; its content is the act that it refers to. To say that a command is a contentindependent reason to obey is to say that its status as a reason to obey depends on features of the container (the speech act), not on features of the content (what the speech act refers to). It is this contrast between container and content that allows us to make sense of commands as content-independent reasons.

This implies an answer to our first question about the nature of content. Content-independence only applies to reasons that have containers as constituent parts. Recall that (on my view) practical reasons are facts that stand in a certain relationship to agents and actions. As examples of reasons we have seen the fact that exercise promotes health and the fact that my parent commanded me to go to bed. The former is a reason for me to exercise and the second is a reason for the child to go to bed. These facts (states of affairs, as I understand them) have constituent parts. The first fact has exercise and health as some of its constituent parts, the second has the command. The fact that my parent commanded me to go 
to bed can be a content-independent reason because it partially consists of a speech act that has referential content, so we can usefully distinguish the content from the container. The fact that exercise makes me healthier cannot be a contentindependent reason because none of the constituent parts of the fact are containers. There is no content in the relevant sense. I have a reason to exercise due to the fact that exercise makes me healthier but this reason is neither contentindependent nor content-dependent on my understanding. ${ }^{23}$ The distinction simply does not apply to reasons that do not have containers as constituent parts.

Interestingly, we can apply content-independence to other sorts of containers like cups: the fact that this cup was a gift from a loved one can be a content-independent reason to drink from the cup. ${ }^{24}$ This application makes sense because we can contrast features of the container (who it reminds you of) with features of the container's content (the liquid, or whatever, in the cup). Normally the reasons to drink from a cup are a function of features of the content of the cup, as when you drink from a cup filled with water in order to quench your thirst. But drinking from a cup that was a gift can be an expression of gratitude or

23. Thus it is not the case that content-dependent reasons are simply "reasons that are not contentindependent reasons," pace Sciaraffa, supra note 5, at 234.

24. The cup is importantly different from the command. Perhaps most importantly, commands claim to be content-independent obligations, not just content-independent reasons generally. There is probably no feature of a cup that could ever be a content-independent obligation, even if there are features that are commonly content-independent reasons. These reasons will often be outweighed by content-dependent reasons; for example, if the cup contains poison, the fact that the poison will kill you is a conclusive content-dependent reason not to drink from the cup. 
connection quite apart from whether the cup contains water or tea or whatever else, so you can have a content-independent reason to drink from the cup. The paired notions of content-independence and content-dependence only apply when the distinction between container and content can be usefully drawn.

Here I do not provide a definition of a container or necessary and sufficient conditions on being a container. ${ }^{25} \mathrm{I}$ intend to use the notion of a container in a commonsensical way. There may be marginal cases where such a definition would be helpful, but my main goal here is simply to show that contentindependence and content-dependence depend on the idea of a container and that not all reasons have containers as constituent parts. This allows us to see when the notions are useful and what they are useful for.

We next need to know in what it means for the reason to be independent of content. The main point of clarification concerns what features of the reason are independent of content. I take the relevant sense of dependence to be a kind of supervenience relation: if some feature of the reason is independent of content then changing the content does not change that feature of the reason.

We can distinguish three features of a reason that might be independent of content: the reason's existence, its weight, and, the action it counts in favor of. ${ }^{26}$ On my understanding, what is important about content-independence is that the

25. Thanks to anonymous reviewer for encouraging me to clarify this.

26. I am using "weight" in a very broad sense to capture what it is about a reason that binds, which is also expressed by other metaphors such as the "strength" of a reason and includes Raz's controversial idea of exclusionary force as a special kind of defeat. 
reason's existence and weight do not depend on content. ${ }^{27}$ That is, features of the container, not features of the container's content, determine whether the agent has a reason of a certain weight. ${ }^{28}$ The content can determine what action a contentindependent reason counts in favor of. ${ }^{29}$ What this entails is that changing the content of a content-independent reason does not change whether the agent has a reason or the weight of the reason, but it does change what the agent has a reason to do.

An example will help. Above I gave the case of a parent commanding a child to go to bed and a variation where the parent commanded the child to eat her peas. If my explanation of content-independence is correct, then the change in content should not change whether the child has a reason or the weight of that reason, but it should change which action the command counts in favor of

27. We could perhaps say that a reason with no weight is not a reason at all, and so subsume the reason's existence to its weight. I think this is probably correct but for purposes of clarity I will keep existence and weight distinct.

28. Compare William A. Edmundson, Three Anarchical Fallacies 13 (1998).

29. This specification matters, for as Markwick, Law and Content-Independent Reasons, supra note 5 , at 594 points out, we surely cannot make sense of a reason that was independent in all ways from its content: this is "an important respect in which legal reasons are content-dependent rather than content-independent." I am specifying other important respects in which reasons can be independent from content, and these respects can be kept distinct in order to capture a property of some reasons that it still makes sense to call "content-independence" even if it is not independent in the most absolute sense. See Gardner, supra note 1, for some further ways that content matters for the reason. 
performing. And this is exactly what we see. The parent's commands are a reason for the child to act in both cases and in both cases the reason is of equal weight but the favored actions are distinct because one is a reason to go to bed and the other is a reason to eat peas as determined by the content of the respective speech act.

If we changed the source of the speech act, as in the stranger case, the existence and the weight change but the favored action does not. The source of the command is wrong, so the child has no reason (of no weight) to go to bed. Note that the favored action is still determined by the referential content of the command: it is precisely a reason to obey and go to bed that the child does not have due to the fact of the command. The stranger's command can be a reason to act in other ways, for example a reason for the child to tell a parent about a nearby, interfering stranger.

In sum: a reason is content-independent iff it has a container as a constituent part and changing the content of that container does not determine whether the agent has a reason and does not determine the weight of that reason. ${ }^{30}$ The existence and weight of a content-independent reason instead depend on features of the container. The paradigmatic case of a content-independent reason is a reason constituted by a speech act (including commands, promises, and requests). In the case of speech acts, we are most often concerned with the

30. A reason is content-dependent iff it has a container as a constituent part and changing the content of that container determines whether the agent has a reason or determines the weight of that reason. 
existence and weight of the content-independent reasons that are determined by features of the source of the speech act. ${ }^{31}$

\section{THE PUZZLE OF UNJUST LAWS}

This explanation of content-independence allows me to clearly respond to one of the idea's most vexing puzzles. If a law imposes a content-independent moral obligation, then according to the understanding I just articulated, changing the content of the law will not change the existence or strength of subjects' reason to do as the law commands. ${ }^{32}$ It is a feature of the container that directly determines the fact that subjects have a moral obligation, not any feature of the content of the particular law. So if citizens have a general content-independent political

31. Features of the speech act other than the source can also constitute content-independent reasons. If you have sensitive hearing, the volume of the speech act can be a content-independent reason for you to cover your ears, for example. Volume is a feature of the container itself, not the content of the container (whether you are being berated or praised, the volume of the speech act constitutes a reason), nor its source (whether your employer or your partner is being loud, the loudness gives you a reason).

32. Not all laws command, of course, as many function to empower or permit, for example, rather than obligate. Obligation is a particular case of an authority's directive changing normative standing, i.e. one way in which authority understood as a Hohfeldian power can be exercised. The puzzling features of content-independence arise for all the various ways authorities can bind subjects and change normative standing. I focus on the case of obligation because it is most familiar and most relevant to the literature, but my analysis of content-independence applies mutatis mutandis to all kinds of authoritative directives. 
obligation, then they are morally obligated to obey every law, regardless of the content of the law.

Yet this cannot be the case. To modern eyes it is obvious that clearly and egregiously unjust laws cannot bind citizens. ${ }^{33}$ If the United States repealed the $13^{\text {th }}$ Amendment and thereby made slavery legal again, laws defining the legal standing of slaves and laws supporting slave ownership would not morally obligate United States citizens to consider others as slaves or support slavery. This would be absurd. Yet we are clearly making this judgment on the basis of the content of the particular law: laws legalizing slavery do not morally bind precisely because slavery is egregiously morally wrong. So content-independence looks like it cannot account for the fact that laws like this do not bind. ${ }^{34}$ George Klosko goes so far as to claim that the notion of a content-independent political obligation is at odds with the entire idea of limited government. ${ }^{35}$

To be as clear as possible about the puzzle: according to the understanding of content-independence I just gave, the reason is independent of content in the

33. Perhaps all laws would bind on views of political authority that take, for example, any actual monarch to be the representative of god's will and exercising god's authority. Yet even these views (and secular views like them, as with Hobbes) impose some limits on the injustice of particular laws; see Klosko, supra note 1, at 504-505.

34. As Green notes, supra note 1, at 47, content-independence must also be made consistent with the fact that "grossly immoral promises do not bind." Compare Hart, supra note 17, at 102. Ultimately, however, I think these problems (and their solutions) will be distinct, as they rest on the distinct natures of promising and command, rather than on content-independence per se.

35. Klosko, supra note 1, at 500; see also 518, n. 5. 
sense that changing the content does not affect the existence or weight of that particular reason. The objection claims that this cannot be the case because egregiously unjust commands do not constitute binding reasons: changing the content of a command to an egregious injustice affects the existence or weight of the reason. So the explanation of content-independence I gave cannot account for a considered judgment about commands. ${ }^{36}$ Something has gone wrong: perhaps content-independence is conceptually incoherent or perhaps it is coherent but fails to explain commands. In either case the search for content-independent reasons in the political sphere is bound to fail, and the whole debate needs to be reframed. ${ }^{37}$

Two notes about this puzzle. First, it is important that it is limited to egregious injustices. The claim is not that every unjust command fails to bind. ${ }^{38}$ As Raz emphasizes, this would contradict the very nature and purpose of authority. Necessarily, some mistaken commands bind. ${ }^{39}$ Otherwise people should just do what the balance of reasons supports regardless of authority, and authorities cannot play the mediating and coordinating role that they do.

36. Compare Raz, supra note 1, at 62. It seems to me that Raz's explanation of the puzzle, which focuses on its consistency with the preemptive character of commands rather than their contentindependence, fails because it appeals to the psychological states of the subject to explain what is a justificatory, normative issue. As Raz himself notes in his discussion of Hart, the preemptive force of commands is not about what is going inside subjects' heads.

37. Klosko, supra note 1 , at $516 \mathrm{ff}$.

38. Pace Klosko, supra note 1, at 504.

39. See Raz, supra note 1, at 61-62, 78-79 for the general point about authority and the particular case of political authorities respectively. 
Understanding authority in this way, to make no normative difference, invites confusion and chaos. This limitation also seems consonant with our experience with the law. We tolerate some perceived injustices, but at a certain point we reject the law's claim to authority.

Second, it will not do to respond to the puzzle by saying that commands are "partly" content-independent. ${ }^{40}$ As Green notes, content-independence is not a matter of degree. ${ }^{41} \mathrm{~A}$ partially content-independent reason is just a contentdependent reason. ${ }^{42}$ The point of identifying content-independent reasons is to separate them from disagreement over the quality of content and so to establish their unusual, but possibly helpful, role. This role is undermined if content comes back into play to any degree. This is a conceptual point. Content-independent and content-dependent reasons will often have to be weighed against one another in practical matters, and just because a reason is content-independent does not mean it is overriding. ${ }^{43}$ But we still need to keep those reasons that are features of the

40. Klosko uses this language and related analogues, but in doing so he is being skeptical about the notion of content-independence.

41. Green, supra note 1 , at 51.

42. Of course, the same fact can constitute more than one reason, and could constitute both a content-independent reason and content-dependent reason. If we have a general political obligation, then we have both content-independent and content-dependent reasons to conform to the law proscribing murder: a content-independent reason because it is the law and a contentdependent reason because we have extra-legal moral reasons to refrain from murder simply because it is murder.

43. The debate over political obligation is so difficult in part because it is about not just whether 
container distinct from reasons that are features of the content, and categorize them accordingly.

In the remainder of this section I solve this puzzle. In short, the solution is that the content affects the container. Egregiously unjust commands can affect the existence and weight of a reason because egregiously unjust commands affect our assessment of the qualities of the source of the command. This does not make such commands into content-dependent reasons. Features of the container, not features of the content, still directly determine the existence and weight of the reason. Unjust commands can fail to bind yet still be content-independent reasons. In these cases the content is relevant, but only indirectly so.

Importantly, however, this solution arises from a particularly instrumentalist, Razian perspective on the grounds of content-independent reasons and authority. I leave it to defenders of other theories (for example, hypothetical consent or democracy) to determine whether content-independence can be consistent with limited government on their accounts. ${ }^{44}$ On Raz's service conception of authority, A has genuine authority over B when B would more likely conform to her reasons by trying to follow A's directives than by following

laws constitute content-independent reasons to act, which they often do in a variety of ways, but whether we have a general content-independent obligations to obey.

44. That said, even theories of legitimacy that are not as thoroughgoingly instrumentalist as Raz's often include issues of reliable performance as a requirement on the justified exercise of political power, e.g. in the guise of a "reasonable likelihood of success" requirement. Insofar as this is true, they may be able to appropriate the solution I use here. 
her own private judgment. ${ }^{45}$

How could we assess whether B would be more likely to conform to her reasons by following A's directives? We cannot consider the content of a particular command and compare it to B's preexisting reasons. First, this would replace the notion of likelihood with a guarantee that B would better conform and would make the reason content-dependent. Second, this is impossible for limited beings like ourselves, who often lack knowledge and appreciation of the relevant reasons. Third, it would render authority useless by making it impossible to coordinate actions in conditions of uncertainty and disagreement about content. ${ }^{46}$ The assessment of whether B is more likely to conform to her preexisting reasons must instead be made indirectly.

Not coincidentally, this indirect assessment is similar in many ways to the assessments that novices must make about experts. ${ }^{47}$ If novices were in a position to judge whether someone is an expert by examining the quality of their work, they would no longer be novices, they would be experts themselves. So instead novices use indirect indicators of expertise. For example, in the case of medical

45. Raz, supra note 1 , at 53. I personally endorse an instrumentalist theory of authority that significantly modifies the Razian approach, which allows a more direct and more clearly motivated solution to the puzzle of content-independence. But the service conception is widely known, widely influential, and is sufficiently relevantly similar to my preferred view, so I use it as the basis of my discussion here.

46. Raz, supra note 1 , at 58-59.

47. Alvin I. Goldman, Experts: Which Ones Should You Trust?, 63 PHILOSOPHY AND PHENOMENOLOGICAL RESEARCH 85 (2001). 
doctors, we use indicators like degrees, certifications, reviews by other trusted experts, and so on. One of these indirect methods is by looking at a track record, that is, at the pattern of success and failure in particular instances. ${ }^{48} \mathrm{~A}$ flawed track record is indicative of some failure that is relevant for the assessment of present ability to act well. ${ }^{49}$ As a part of a track record, then, the content of a command can be relevant as one indirect way that assessments of authority get made. This opens the door for a solution to the puzzle.

In the case of egregious injustice, the problem is not just that this particular command is mistaken. Egregious injustices infect our assessment of someone's judgment on the whole. ${ }^{50}$ If the US government repeals the $13^{\text {th }}$ Amendment, it is not just that particular command that fails to bind. We citizens

48. How can novices judge track records, if that is a function of content? Some kinds of successes will be relatively obvious: doctors curing diseases, for example. Other successes become obvious in retrospect, like the predictions of astronomers about the time of an eclipse. See Goldman, supra note 46, at 106-108. As an anonymous reviewer pointed out to me, the egregious injustice is not quite the same as a track record considered as a diachronic pattern of past performance. Instead it is more akin to a physician who negligently killed a patient. The point in either case is that the quality of the result can be assessed even by non-experts and matters (a great deal) for how we judge the quality of the agent's capacities more generally.

49. Consider the boy who cried wolf.

50. The details of this "infection" would have to be carefully spelled out, especially in relation to the piecemeal nature of authority on a Razian account. Although I cannot address this issue here, on my view the extent and limits of the infection are demarcated by issues of trust and trustworthiness, analyzed along the lines of Annette Baier, Trust and Antitrust, 96 ETHICS 231 (1986). 
now have excellent grounds for doubting the judgment of the government in future cases as well, not just in this case. If the US government thinks that allowing slavery is permissible, especially after our horrible history, then its judgment is fundamentally flawed. Failure to appreciate the clear and decisive reasons against slavery shows that the government cannot appreciate the most basic reasons of the kind it needs to rule, let alone the nuanced and difficult reasons that are relevant to political questions. ${ }^{51}$

When $\mathrm{A}$ issues a command to perform an egregious injustice, it is true that this command is not a reason for B to perform an egregious injustice. But that is not because this one command fails. It is because A loses her authority in the very act of commanding an egregious injustice. Future commands from A would also fail to constitute reasons for $\mathrm{B}^{52}$ The content of the egregiously unjust command is relevant to the overall assessment of A's judgment, and so is relevant to

51. Notice that the way the decision poisons our assessment of the government's judgment as a whole is a function of the clear egregiousness of the decision, not the mere fact that it is an injustice. This is consistent with our considered judgments (slightly unjust laws can bind) as well as with our understanding of authority (some mistaken commands must bind).

52. We could, I think, imagine cases where a mistake was a blip in A's judgment and she rehabilitates herself to the point where she has authority over B again (especially in the case of large and complex institutional authorities, where a rogue official might explain a blip). But this could not happen immediately; the correct description of the case would be that she lost authority for a while and then regained it, not that she had it throughout. Further, the more egregious the mistake, the less likely that it could be a blip. For a variety of reasons, legalizing slavery again could not reasonably be considered a blip. 
whether A has authority over B. The egregiously unjust command makes it the case that A loses her authority, so that particular command and future commands all fail to bind.

Recall that content-independent reasons depend on features of the container. In this case, the content was relevant to the features of the container, and so indirectly changed whether there was a reason. ${ }^{53}$ But the existence of the reason is still determined by a feature of the container, not a feature of the content. When the content does not affect the container despite the demerits of the content, as in the case of slightly unjust commands, the subject still has a reason because the content is not the determinant.

So the content was relevant to the existence of the reason, but only indirectly by being relevant to whether A has authority at all. This does not undermine the claim that the commands of genuine authorities constitute contentindependent reasons. ${ }^{54}$ This is, I believe, the only satisfying explanation of how

53. We can also imagine an analogous case where the content of a cup infected the container and resulted in content-independent reasons not to drink from the container, as when a cup becomes irradiated by some radioactive content. The container's features are changed such that even if you filled it with fresh water, you would have reasons not to drink from it because the cup itself would harm you. The radioactive content was indirectly relevant to whether you have a reason to drink from the container, but only because it changed the container itself; features of the container still determine the existence and weight of the reason.

54. I think a similar solution works for those who worry about authority's scope, for example Sciaraffa, supra note 5, at 240 and Klosko, supra note 1, at 506. Content is indirectly relevant for considerations of scope insofar as content determines the favored action, but this does not 
content-independence can be consistent with the fact that egregiously unjust commands fail to bind.

\section{CONCEPTUAL CHALLENGES}

My understanding of content-independence also provides the resources to respond to two challenges to content-independence in the literature. P. Markwick claims that the idea of content-independence is either conceptually incoherent or useless. ${ }^{55}$ Stefan Sciaraffa claims that it can be made coherent and useful, but only by jettisoning any reference to the idea of content. ${ }^{56}$ I will show that my account is not subject to Markwick's criticisms and that Sciaraffa's account mischaracterizes some reasons.

Markwick's main argument is that content-independence is a feature of all reasons, so cannot be used to fruitfully analyze concepts like commands because it does not identify a distinguishing feature of those concepts. ${ }^{57}$ Compare the

implicate content-independence properly understood. This topic is complex and I cannot address it here.

55. Markwick, supra note 5.

56. Sciaraffa, supra note 5.

57. Notably, I accepted one of Markwick's other arguments showing that the favored action must be determined by content. Also, Markwick is careful to note that he does not consider all possible understandings of content-independence and was trying to reconstruct the idea from brief and often vague discussions. One way of seeing my argument here is as proposing an understanding that Markwick does not consider and is immune to his challenges. 
following reasons for Alice to $\phi$ : because she was commanded to $\phi$ and because $\phi$ ing maximizes utility. It appears that the command is a content-independent reason for Alice to $\phi$ because we could specify $\phi$-ing in any way and Alice would still have reason to $\phi$. Whether a reason to $\phi$ exists depends solely on whether the property "being commanded" obtains, so is independent of the particular specification of $\phi$.

But Markwick notes that the same is true of Alice's other reason as well. ${ }^{58}$ For any $\phi$, if $\phi$ maximizes utility then we have a reason to $\phi$. The existence of the reason depends on whether the property obtains and not how $\phi$ is specified, so is independent of its content. Maximizing utility suddenly appears to be a contentindependent reason as well. Furthermore all reasons, not just maximizing utility, will pass this test, seemingly due to the simple fact that they are reasons so apply across cases. If this is true then content-independence is a feature of all reasons and does not distinctively identify reasons given by commands or anything else, so should not be used to characterize or analyze some subset of reasons.

My understanding of content-independence is not subject to this argument precisely because Markwick and I disagree about what counts as content in the relevant sense. ${ }^{59}$ Markwick does not restrict the notion to reasons that have

58. Markwick, Law and Content-Independent Reasons, supra note 5, at 591 and Independent of Content, supra note 5, at 58.

59. Confusion about the nature of the content is not restricted to Markwick. As we will see below, Sciaraffa's theory leads him to restrict his attention to the content of intentional acts and Gur, supra note 1 , restricts attention to the content of requirements. A virtue of my account is how it 
containers as their constituent parts, instead assuming that the relevant content is the action that the reason counts in favor of rather than the content of some constituent part of the reason. Markwick argues that the fact that $\phi$ maximizes utility is a content-independent reason to $\phi$ because whether $\phi$ maximizes utility is independent of $\phi$. On my view this reason cannot be content-independent because it does not have any containers as constituent parts.

Why not think the reason itself is a container? The standard treatments of content-independence seem to imply this; discussion of the content of the reason is rampant. But, as I show below, these discussions occur in the context of reasons that are themselves speech acts and so have content on my understanding. Reasons in general are facts, i.e. states of affairs, like the fact that I was commanded to $\phi$. The facts themselves have no content on their own (even if our statements of the facts do). The fact that I was commanded to $\phi$ does not "contain" the command, it is simply partially constituted by the command. Loose talk of the content of reasons in contexts where the relevant reasons are containers should not lead us to the view that reasons per se have content.

There seem to be two main reasons that Markwick applies contentindependence to all reasons: first, in defining content-independence no theorist has heretofore explicitly restricted its application to containers. Recall Raz's definition: "A reason is content-independent if there is no direct connection

captures the breadth as well as the limitations on the contexts in which content-independence can be usefully applied. 
between the reason and the action for which it is a reason. ${ }^{, 60}$ Since there is no restriction this appears to apply to any reason whatsoever.

Second, Markwick claims there are instances where some theorists have ascribed content-independence (or -dependence) to non-containers. It may be the case that we could find some instance of this. But the two cases Markwick relies on are infelicitous. Markwick claims that Raz refers to penalties as contentdependent reasons ${ }^{61}$ and that Leslie Green ascribes content-dependence to considerations of utility. ${ }^{62}$ In context, however, both are considering containers.

In the text Markwick refers to, Raz does not refer to penalties at all. That aside, Raz does consider threats to be a sort of reason. And in the case of threats, we can see how penalties do constitute a content-dependent reason on my view. The threat is a speech act and the threatened penalty is part of its content. The reason to comply with the threat changes if we change the threatened penalty. If the robber says "If you do not give me your wallet, I will kill you," you have very strong reason to hand over your wallet. If the robber says "If you do not give me your wallet, I will weakly poke you in the arm," you have hardly any reason at all to hand over your wallet. So penalties can be content-dependent reasons when

60. Raz, supra note 1 , at 35 .

61. Markwick, Independent of Content, supra note 5, at 44 n. 6 and at 45 n. 9. See also Markwick, Law and Content-Independent Reasons, supra note 5, at 580 n. 5, although there is no explicit reference to Raz in this case.

62. Markwick, Law and Content-Independent Reasons, supra note 5, at at 587 n. 22 and Independent of Content, supra note 5, at at 45 n. 9. 
they are the content of a threat. Insofar as Raz is concerned with penalties at all, it is when they are part of a threat, so do not stand as a use of content-independence or -dependence outside the context of a container. ${ }^{63}$

Markwick's reading of Green encounters the same problem. Green does indeed refer to considerations of utility as content-dependent. But he does so in the context of considering the reasons subjects have to obey a command or follow a social norm. Consider a social norm to $\phi$; the norm is the container and the referential content of the norm is $\phi$. What reasons do you have to conform to the norm? You have the content-independent reason to conform to the norm because of the fact that a social norm requires $\phi$-ing, but you also often have contentdependent reasons to conform to the norm because of the nature of $\phi$-ing, like the fact that $\phi$-ing generates a net gain in utility. The former reason is contentindependent because changing $\phi$, i.e. changing the container's content, does not change the fact that a social norm requires it, so does not change whether you have a reason or that reason's weight. The latter is content-dependent because whether you have a reason and the weight of your reason depends on how $\phi$ is specified because that will change whether, and to what extent, there is a gain in utility.

The contrast between these sorts of reasons is common, which Green highlights with his discussion of indirect consequentialism. The whole advantage

63. Raz argues threats are content-independent reasons to believe, not practical reasons at all. The correct analysis of threats is not our point, however; our point is that the notion of contentindependence is still being used in the context of a container. 
of indirect forms of consequentialism is that I can take the content-independent reasons I have to obey a rule or follow a norm (like the fact that it is part of a utility-maximizing set of rules) as decisive, thus avoiding the costs of calculating the utility-based reasons to $\phi$ that are constantly changing according to how $\phi$ is specified and its features in a given context. These utility-based reasons to $\phi$ are content-dependent when considered in relation to a rule or norm to $\phi$, not simply content-dependent in general. It is only in the context of considering the content of containers that Green concerns himself with considerations of utility. This is precisely where content-independence comes into play and the controversy over political obligation has its bite.

That said, Markwick may be correct that some people have used contentindependence in the way he describes and that usage may well be incoherent in the way he argues. But we need not follow the way the idea has been used by others, so I conclude that Markwick's arguments do not show that my understanding of content-independence is incoherent or useless. ${ }^{64}$ His arguments do not apply to an understanding of content-independence that is restricted to container reasons and we have no good reason to extend the notion of contentindependence beyond containers.

Interestingly, although content-independence and content-dependence are applied almost exclusively to speech acts, there are two instances that I know of where they are not. Raz says that rules are content-independent reasons but

$\overline{64 . ~ N o t e ~ m y ~ q u a l i f i e r, ~ s u p r a ~ n o t e ~} 57$. 
explicitly denies that they are speech acts ${ }^{65}$ and Andrei Marmor refers to contentdependent reasons to follow a map. ${ }^{66}$ It is clear that rules are referential containers just like speech acts and we can make sense of a map as a referential container as well, as its features are meant to refer to features of the area. These applications of content-independence are consistent with my understanding that restricts itself to containers but not solely to speech acts.

My understanding of content-independence also shows why Sciaraffa's proposed account is off track. Sciaraffa finds inspiration for his analysis in Hart's discussion of commands. For Hart a command both expresses the authorities' intention that subjects act in particular way and expresses the authorities' intention that the subjects act in that way because the authority so intended. So it is not enough to do what an authority says, you must do what they say because they say it. Call this feature of commands their "reflexive intention." Sciaraffa

65. Raz, supra note 7, at 48 and 51; compare Shapiro, supra note 1, as well as Himma, supra note 1 , at 27 , where he ascribes content-dependence to moral norms.

66. Marmor, supra note 1 , at 346. I think Marmor is actually mistaken about maps only ever constituting content-dependent reasons. In the normal case, this is true. But imagine that you found the map of a distant ancestor and wanted to follow in her footsteps. In this case you do not care whether the map is accurate, you only care that it was your ancestor's map because you care about the journey and not the destination. It is a feature of the container (provenance), not the content (accuracy), that provides the reason for you to (for example) follow a certain path. Of course changing the content of your ancestor's map would change what trail you should follow, but this is consonant with my understanding of content-independence as it changes the favored action but not the existence or weight of your reason. 
argues that reflexive intention is what defines content-independent reasons. ${ }^{67}$ (I think reflexive intention is importantly characteristic of commands, following Hart; my disagreement with Sciaraffa is that it captures content-independence.) According to Sciaraffa, you have a content-independent reason to $\phi$ if and only if someone's reflexive intention is a reason for you to $\phi$.

This move appears to lead Sciaraffa to restrict his view to speech acts, so content-independence only applies to containers on his view. There are two problems. First, it applies only to speech acts but content-independence is a sensible notion to apply to other sorts of containers as well, as I showed above in the case of the gifted cup. Second, and more importantly, the focus on intention is misleading because a speech act can be a content-independent reason without meeting Sciaraffa's test.

Consider the following case. A man works for an investment fund that happens to be run by his mother and he advises her to purchase a certain stock, stock A. The mother knows the advice to be bad but purchases stock A anyway in an attempt to soothe her contentious relationship with her son. The son did not intend for his mother to purchase the stock because he said so, he intended her to purchase the stock because purchasing the stock is a good idea on its merits, as revealed by his good advice. He was trying to show that he was a quality employee, not attempting to encourage nepotism. As advice, his speech act was supposed to constitute a reason for his mother to act only if its content had merit.

67. Sciaraffa, supra note 5, at 234, 246, and 254. 
On Sciaraffa's account, then, the son's speech act cannot be a contentindependent reason because the son did not intend the mere fact of his speech act to be his mother's reason for acting, i.e. the son lacked the relevant reflexive intention.

However, it is clear that the speech act was a content-independent reason for the mother. The mere fact that it was her son's speech act gave her reason to buy that particular stock even though it was a bad stock. If her son had said to buy stock B, she would have had the same reason to buy stock B as she had to buy stock A because she can achieve her goal of appearing to respect her son's judgment regardless of the stock. And if some other employee had said to buy stock A, she would not have had reason to buy it because the source of the speech act was wrong, given her aims.

This aligns perfectly with my understanding of content-independence. It is a feature of the container, the speech act's source, that determines the existence and strength of the reason she had to buy the stock. Changing the content does not change those features of the reason but changing the source does. So the son's advice is a content-independent reason for the mother even though he did not intend it to be.

Of course it may well be the case that all-things-considered she should not have acted on her content-independent reason. The facts that she is deceiving her son, that she is risking him finding out and worsening their relationship, that she is using her professional position for personal reasons, and that she is risking losing money on a bad investment all count against acting on her content- 
independent reason to buy stock A. But those facts do not show that she lacks a content-independent reason, just that her reason is outweighed.

Notice that, regardless of the son's intention, the advice constitutes a variety of content-independent reasons. ${ }^{68} \mathrm{I}$ focused on the mother's contentindependent reason to buy the stock. But the fact that my son advised me to buy stock $A$ also constitutes other content-independent reasons. For example, even if the mother treats the advice merely as advice, the fact that her son gave her the advice means that she has a content-independent reason to treat her son as responsible for giving the advice, she has a content-independent reason to inform her son, not anyone else, whether she took the advice, and so on. These are content-independent reasons because their existence and weight are determined solely by features of the container, including features of the source like his identity and institutional role, not by the content of the speech act. Whether the advice is good or bad, she has reason to inform her son of her response because he was the source of the advice. Had some other employee given her the same advice, she would have a reason to inform them instead because the reason to inform depends on features of the container, not the content; had some random person that she stands in no institutional relationship to given her professional advice, she might not have a reason to inform them of her response at all. All speech acts will constitute a variety of both content-independent and contentdependent reasons of this rather banal kind.

It is important to see the application of content-independence in these sorts

68. Thanks to an anonymous reviewer for pushing me on this point. 
of cases, apart from the context of commands and the accompanying complicating factors of illocution and preemption. Standardly understood, commands demand obedience, not merely in the sense of doing as commanded but doing as commanded because one was commanded to do so, i.e. by recognizing and appropriately responding to the speaker's reflexive intention. Reasons to obey, then, can only obtain when one was commanded; if you do as someone says but there was no command, you have not obeyed in the strict sense. So the reflexive intention that is partly constitutive of commands is necessary for a speech act to be a content-independent reason to obey because of the nature of obedience, but content-independent reasons for other sorts of actions are commonplace, especially with respect to speech acts, and do not depend on the speaker having a reflexive intention.

My overall point that Sciaraffa's account is mistaken is established simply by the fact that the content-independent reason exists without the son having a reflexive intention. Sciaraffa's account also distances itself from the original understanding of content-independence by ignoring the notion of content entirely, claiming that the term is a "misnomer" and "misleading." 69 My account avoids the unfortunate implication that all the theorists who defined contentindependence in terms of content and thought that content was important were badly mistaken.

\section{POLITICAL OBLIGATION}

69. Sciaraffa, supra note 5, at 235. 
The final issue I will address is Klosko's attempt to reframe the debate over political obligation. He "criticize[s] content independence directly" and ultimately concludes that we should reject the search for content-independent political obligations, instead focusing on content-dependent political obligations. ${ }^{70}$ His discussion is wide-ranging and a full treatment would take us far beyond the scope of this paper. I will not address many of the considerations he raises because my goal is not a complete discussion of or response to Klosko. (Indeed, I agree with some of Klosko's substantive conclusions but take exception to his framing of the problem in terms of content-independence.) Instead, my point is that the understanding of content-independence we have come to in this paper brings some clarity to his assertions and ultimately suggests that the debate over political obligation cannot be fruitfully recast in the way he claims.

A helpful way to enter the debate over political obligation is with a very practical question: when faced with a law that requires me to act in some way, what reasons do I have to act as the law requires? The most obvious reasons are the content-dependent reasons, having to do with the merits and demerits of acting in the particular way specified by the law. To take the philosophical anarchists' favorite example, when faced with a stop sign there are often reasons for me to stop because stopping prevents me from rushing into an intersection at high speeds, risking the safety and welfare of myself and others. But, and this is part of the anarchists' point, these content-dependent merits of obeying the law

70. Klosko, supra note 1, at 499 . 
requiring me to stop change from context to context. If I am in the middle of a flat desert, in the light of day, without any sight obstructions, and I can see that there is no risk of an accident, it appears that there are no merits to obeying the law and stopping. It is just a waste of time and gas. Do I have any reason to obey when I lack content-dependent reasons?

If my reasons to do as the law says are exhausted by content-dependent reasons, a variety of problems arise. First, because they change according to context, citizens must constantly reevaluate whether they have reason to do as the law says, resulting in significant inefficiencies. Second, and more worryingly, the law loses its ability to coordinate actions in situations of fundamental pluralism and disagreement. We disagree about what the content-dependent reasons are, so we disagree about when we have reason to do as the law says we must. Yet this undermines the coordinative goals of political institutions, which require most citizens to obey most laws most of the time. ${ }^{71}$ The government achieves coordination by upholding the law even when citizens deny that they have an obligation to obey on content-dependent grounds (and even sometimes when the citizens are correct about this). Third, the content-dependent reasons will often be obscure to ordinary citizens, who do not have the time or expertise to evaluate the grounds of the huge volume of complex laws in modern society.

71. The law can, of course, tolerate a certain amount of nonconformity in both theory and practice. The point is that nonconformity cannot be a fundamental and pervasive feature of the system. See Christopher Heath Wellman and A. John Simmons , Is ThERE A DUTY TO OBEY THE LAw? 168169 (2005). 
These problems for relying solely on content-dependent reasons are connected to the nature of authority. Authorities demand that subjects defer, or that they surrender their will, or that they replace their private judgment with the authority's judgment. ${ }^{72}$ As Raz emphasizes, the whole point and value of authority is captured by the mediating role that deference enables. ${ }^{73}$ Authority abstracts away from the merits of particular commands and generates reasons based on who issued those commands. It thus bypasses debate and disagreement about the nature of underlying, fundamental reasons. There is "enormous" value in this mediating role, not only for purposes of coordination and efficiency, but for the possibility of a "pluralistic culture." 74 A genuine authority achieves these advantages by issuing commands that constitute content-independent (and preemptive) reasons. ${ }^{75}$

Given the problems with relying only on content-dependent reasons, the alternative is that I should obey a particular law for content-independent reasons. On the understanding of content-independence that I articulated in section one

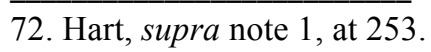

73. See Raz, supra note 1, at ch. 3, especially 58-60.

74. Raz, supra note 1 , at 58.

75. This is absolutely central to Raz's view. Klosko, supra note 1, claims in endnote 5 that Raz's view is actually content-dependent, giving two reasons. One is that political obligations are not compatible with clear injustices, which I addressed above. The other is that it is limited in scope. Neither of these tells against content-independence. Further, this would be a massive, fundamental revision of Raz's view, given his discussions of content-independence. He says that the focus on the speech act rather than its content is of "great importance." Raz, supra note 1, at 35. 
this means that there is some feature of the container that determines whether I have a reason and the weight of that reason. ${ }^{76}$ The debate over political obligation comes down to whether there is any feature of a law that can be a reason amounting to a moral obligation, disregarding the features of the content of the particular law. ${ }^{77}$

The disagreement between philosophical anarchists and statists can only be understood with the distinction between content-dependent and contentindependent obligations to obey the law. For example, the most prominent and influential philosophical anarchist, A. John Simmons, admits that there often are good content-dependent reasons to obey laws, including some obligations to obey. ${ }^{78}$ What he denies is that states have the authority to issue laws that correlates to a general content-independent obligation to obey. Statists do not deny that there are good content-dependent reasons to obey many laws, nor do they deny that these reasons should often motivate citizens to obey. They claim that, in addition, states have the general authority to issue and enforce laws independent of their content. ${ }^{79}$

76. Recall (supra note 26) that "weight" is being used to include exclusionary force. Whether the command constitutes an obligation still depends on features of the law and not features of the content, regardless of whether we regard the bindingness of the obligation in terms of weight or exclusion.

77. Compare Hart, supra note 17, at 104.

78. See, e.g., Simmons, supra note 2, at $194 \mathrm{ff}$.

79. Again, some restrictions on content are consistent with content-independence as I have defined it, including most importantly the limit on egregiously unjust laws that I discussed in section two. 
Why, then, does Klosko think that moving to content-dependent views of political obligation is fruitful? The answer is that he mischaracterizes contentindependence and the debate over political obligation. ${ }^{80} \mathrm{He}$ says that he will understand citizens to be under a content-independent political obligation when they have an obligation to obey the law "because it is the law." I will call this a "purely legal" reason. He distinguishes this from citizens who have an obligation that is "independent of content," but not for purely legal reasons. He calls these "formal reasons." Examples of formal reasons include considerations of coordination, fair play, gratitude, and democratic decision-making. ${ }^{81}$ His argument for the move to content-dependent views relies on the claim that formal reasons are not to be understood as part of content-independent views. This is mistaken.

The mistake is not the claim that there is a distinction between purely legal and formal reasons. As Klosko correctly points out, much of the historical debate has been framed in terms of purely legal reasons and there are positions that endorse purely legal political obligations. ${ }^{82}$ (These include, for example, positions

80. Klosko, supra note 1 , at 501. It is also worth noting that Klosko relies on Markwick's definition of content-independence, which is strange because Klosko does not claim that the search for content-independent political obligation fails on conceptual grounds, but rather that purely legal reasons cannot establish such an obligation for substantive reasons. Yet on Markwick's definition, purely legal reasons (and any other reasons) would fail to establish any coherent and useful content-independent political obligation as a conceptual matter.

81. Klosko, supra note 1, at 511-514, 517.

82. George Klosko, Content-Independent Obligations: A Reply to Kevin Walton, 42 PoLITICAL 
that ground obligation in delegated divine authority to any extant political leader and positions that ground obligation in the fact that effective political institutions constitute escape from the threats of the state of nature. ${ }^{83}$ ) The mistake is to think that formal reasons are not content-independent reasons. Content-independence frames the debate over formal reasons and to reject this characterization is to misconstrue important elements of this debate.

There is an oddity to Klosko's discussion that brings out his error. He says that formal reasons are "independent of content", and notes that they "satisfy the conditions for content-independence," but immediately stipulates that formal reasons fall under content-dependent views. ${ }^{84}$ Content-independent views, on his definition, are those views that only include purely legal reasons. The question is whether we have reason to follow his way of carving up the conceptual space.

There are good reasons to resist this definition and keep views that appeal to formal reasons in the content-independent camp. ${ }^{85}$ First, formal reasons and purely legal reasons share important features, speaking in favor of classifying

THEORY 223 (2014), at 224-225.

83. See Klosko, supra note 1, at 504-505.

84. Klosko, supra note 1, at 500-501.

85. Kevin Walton, The Content-Independence of Political Obligations: A Response to Klosko, 42 Political Theory 218 (2014) argues to a similar conclusion. Walton's main point does not directly address content-independence, instead focusing on a distinction on how reasons arise in relation to the will and actions of agents. My argument revolves around what substantive issues the notion of content-independence highlights and what those issues bring to the debate over political obligation and authority, so is very different. 
them together (although not therefore collapsing the distinction between them). Second, Klosko's justification for classifying them separately is questionable.

The main reason to deny that content-dependent views can appeal to formal reasons is that formal reasons and purely legal reasons play the same role in the debate precisely because they are content-independent reasons. This role is distinct from the role of content-dependent reasons and gives rise to distinct challenges and prospects. This point arises again in terms of the practical question I opened this section with: why should I obey this law? When we appeal to content-dependent reasons, we are appealing to exactly the sorts of considerations that people are familiar with and that usually count as reasons in favor of acting in some way. As I stated in section one, the most distinctive and important feature of content-independent reasons is that they sever this normal connection between the merits and demerits of an act (the content-dependent reasons) and the act itself.

Formal reasons and purely legal reasons share this puzzling feature. When someone asks why they should obey some law and act in the way that is required by that law, both purely legal reasons and formal reasons appeal to something other than the merits of the act required by the law. Instead they appeal to some feature of the container. This appeal is puzzling in a way that the normal contentdependent reason is not. The difficult question that both types of reasons must answer is why features of the container are relevant for acting in the way specified by the content.

Solving this problem is notoriously difficult. To see why, consider two of Klosko's examples: the Pauline purely legal reason to obey the law as an act of 
deference to divinely appointed rulers and the democratic formal reason to obey based on equal respect for others. Due to the fact that both of these reasons abjure the merits of the law in question and instead appeal to a feature of the law (or lawmaking process) in general, the citizen has several open questions: why should obeying this law on this occasion be construed as a rejection of divine authority or equal respect? It may be true of some laws, some of the time, but why all the laws, all the time, regardless of content? Is going through the desert stop sign really disrespectful of my co-citizens? Further, is it disrespectful in a way that could ground a moral obligation? All these questions arise for both the formal reason and the purely legal reason precisely because they are contentindependent, appealing to the features of the container rather than merits of the act specified by the content. To see how difficult these questions are, one need only look at democratic theory and its ongoing struggle to answer them. ${ }^{86}$

Klosko claims that finding formal reasons that ground an obligation to obey the law "will not be overly difficult." ${ }^{\wedge 7}$ This mischaracterizes the debate.

86. Thomas Christiano, The Authority of Democracy, 12 The Journal of Political Philosophy 266 (2004); Niko Kolodny, Rule Over None I: What Justifies Democracy?, 42 PHIL. \& PUB. Aff. 195 (2014) and Rule Over None II: Social Equality and the Justification of Democracy, 42 PHIL. \& PuB. AfF. 287 (2014); Daniel Viehoff, supra note 1. Again, these questions may very well be answerable. My contention is just that Klosko's classification incorrectly implies that they are "not overly difficult" to answer.

87. Klosko, supra note 1, at 516. Note, as Gur, supra note 1, at 183 says, it may not be difficult to find content-independent formal reasons, but this is quite distinct from finding contentindependent formal obligations, let alone a general content-independent formal obligation. 
Simmons' influential anarchist arguments consider the formal reasons that Klosko appeals to, like coordination, fair play, and democracy. He concludes that none can ground a general obligation to obey the law. He may be wrong, but certainly a fair assessment of the debate cannot claim that finding the connection between formal reasons and obligations to obey the law is not a significant challenge. The power of the anarchists' arguments against formal reasons in particular is a large part of why the literature is increasingly sympathetic to skepticism about political obligation. Folding formal reasons into content-dependent views thus disguises important features of the ongoing debate.

Further, answering these difficult questions in the case of either purely legal reasons or formal reasons has important implications that are distinct from content-dependent reasons, again precisely because they are both contentindependent. These implications are tied to the benefits of authority that I outlined above. If we can successfully give an explanation for why obeying the law is a necessary act of respect for the equal standing of others, then we can forego debates about the qualities of particular laws. It allows us the benefits of efficiency, coordination, and pluralism precisely because we do not have to agree about the content-dependent reasons. Instead we agree about features of the law qua container and obey for those reasons. These same benefits are possible if we could explain the purely legal reason why obeying the law is a necessary act of deference to divine authority. It stands at a higher level of generality because it is about features of the container, not features of the content.

The second issue is the questionable grounds that Klosko gives for his 
classification of the respective views. Recall, I agree that there is some use to distinguishing formal reasons from purely legal reasons and the theories that appeal to them. (I think the distinction is best understood as between purely legal reasons that claim to apply to all legal systems as such and formal reasons that apply only to some legal systems that meet substantive conditions, for example democratic ones.) Klosko, though, does not merely distinguish them; he also claims that formal reasons should be considered a part of content-dependent views. He argues that the moral force of formal reasons "passes through" these reasons to the content of the particular law, unlike purely legal reasons. This "passing through" is what makes formal reasons sufficiently like contentdependent reasons to allow content-dependent views of political obligation to appeal to them while remaining content-dependent views.

For example, Klosko's favored formal reasons are considerations of fair play. On my view fair play reasons are content-independent because it is a feature of the container (the fact that the particular law is one part of the larger cooperative scheme that citizens benefit from) that determines the existence and weight of the reason, not any feature of the content of the particular law. Are they somehow content-dependent as well? Klosko writes,

There is a sense in which the resulting obligation is [contentindependent], as it is to do what government says he should. But the moral force of this requirement is clearly do [sic] his fair share in providing the public goods because of his own need for defense and obligations of 
fairness owed to his fellow citizens, with the moral force of the latter passing through to the laws in question. ${ }^{88}$

There are two problems to address. The first is what moral force "passing through" exactly means. Consider again the law to stop at stop signs. It seems the idea is that if you have a duty of fair play to do your part in a cooperative scheme and the moral force of that passes through to the content of the law, then we can say that it is unfair for you not to stop. The content of the particular law has taken on the moral character of laws in general; that is, it has taken on considerations of fairness.

But this reason is still paradigmatically content-independent. If a citizen asks why they should stop in any particular case, the appeal to fairness is still disconnected from stopping. Why is unfair to not stop? Not because of anything to do with stopping per se. It is only unfair because of some feature of the particular law, the container, namely its place in a cooperative scheme. If stopping was not part of the cooperative scheme in this way, the moral force of unfairness would not have passed through. So the fair play theorist still has to answer the distinctive problem of content-independence, namely how to connect a particular act specified by the content to apparently extraneous features of the container. This will be markedly different from an argument showing why people have an obligation to not murder, for example, which can appeal directly to the features of murder. And so we are right back to the distinct role content-independent reasons

88. Klosko, supra note 1, at 517. 
play in the debate. Due to the fact that fairness is a feature of the container, so is independent of the merits of acting as specified by the content, anarchists like Simmons have ample room to argue that fairness considerations cannot ground a general moral obligation and so do not necessarily pass through to every case of, e.g., stopping at stop signs. ${ }^{89}$

The second problem is whether "passing through" actually distinguishes formal reasons from purely legal reasons. On the Pauline view of purely legal reasons, citizens have an obligation to obey because obedience to the ruler is obedience to god. Surely the moral force of this purely legal reason passes through to the particular law in some sense. If the king says you have to bow before him, his divinely delegated authority makes it the case that not bowing is not only illegal but sinful as a repudiation of divine authority. The moral force of not bowing thus takes on the character of the purely legal reason. If this is right (and we cannot really know without a much clearer understanding of "passing through"), then this is not a helpful way of distinguishing purely legal from formal reasons.

I conclude that we have good reasons to resist Klosko's attempt to include formal reasons in content-dependent views and so we should also reject his larger goal of refocusing the debate over political obligation by abandoning the concern with content-independent reasons. ${ }^{90}$ Formal reasons have the distinctive features

89. Simmons, supra note 2, ch. 5.

90. Within the category of content-independent views, focusing on formal reasons rather than purely legal reasons seems eminently reasonable to me and also seems to characterize how the 
of content-independent reasons and the distinction Klosko draws between purely legal reasons and formal reasons does not show that formal reasons are somehow more content-dependent. Further, Klosko's discussion of content-independence mischaracterizes significant features of the modern debate over political obligation and political authority. The interesting question is what features of laws other than their content could possibly ground a moral obligation to obey regardless of content. Answering this question requires grappling with the distinctive features of content-independent reasons and solving this question allows one to capture the distinct benefits of abstracting from the controversial and contextual characteristics of content.

To briefly conclude: I argued that a reason is content-independent iff it has a container as a constituent part and changing the content of that container does not determine whether the agent has that reason and does not determine the weight of that reason. This understanding is distinctive in restricting contentindependence and content-dependence to reasons that are containers and thereby clarifying how reasons can relate to content. This allows us to solve the vexing puzzle of how content-independent reasons (and especially obligations) can be consistent with the considered judgment that egregiously unjust commands cannot bind.

My account also avoids conceptual challenges to the coherence and usefulness of content-independence and can be used to analyze other content-

literature has generally evolved. Klosko's push to a more piecemeal approach is also plausible to me, but it is orthogonal to the issue of content-independence. 
independent reasons, like those constituted by requests and promises. Finally, my explanation of content-independence clarifies what is at stake in the debate over political obligations and political authority. This simply clears the way for addressing the more interesting and difficult questions of whether and under what conditions laws actually constitute binding content-independent reasons. 